\title{
Anaesthetic management of children with craniopharyngioma
}

\author{
Srilata Moningi
}

\begin{abstract}
The perioperative management of craniopharyngioma in children is quite challenging not only to the neurosurgeons and anaesthesiologists but also to the oncologists, endocrinologists and intensivists. The various concerns include size of the tumour and its effects on intracranial pressure, vicinity of the tumour to nearby vessels and neural structures, endocrine disturbances, compressive symptoms, paediatric age, obesity-related problems, high recurrence rate of the tumour, undesired effects of radiotherapy, high morbidity and mortality. As anaesthesiologists, we deal with most of the challenges. The success of the outcome depends on the proper identification of the patient, pre-operative optimisation, surgical decision, awareness of the complications, timely intervention and optimal post-operative care.
\end{abstract}

Key words: Anaesthesia, children, craniopharyngioma, perioperative

\section{INTRODUCTION}

Craniopharyngiomas are rare and benign epithelial tumours emanating along the path of craniopharyngeal duct. ${ }^{[1]}$ It is the most common suprasellar intracranial non-glial type of tumour seen in children. The management of craniopharyngioma is quite challenging and involves a team effort for effective planning, execution of the treatment and post-operative (PO) care. ${ }^{[2]}$ The anaesthetic management requires a clear understanding of the endocrinological disturbances, surgical extent of the lesion, presence of hypothalamic involvement, increased intracranial pressure (ICP) and urgency of treatment. The 10-year survival rate following gross total resection of these tumours is around $86 \%-100 \%(95 \%)$, so a good perioperative care is an important component for the overall outcome.

Department of Anaesthesia and Intensive Care, Nizam's Institute of Medical Sciences, Hyderabad, Telangana, India

Address for correspondence:

Dr. Srilata Moningi, Flat No. G-3, Sujatha Sterling Homes, H.

No. 8-2-403/A, Road No 4, Banjara Hills, Hyderabad - 500 082,

Telangana, India.

E-mail: srilata_m1973@yahoo.co.in

\begin{tabular}{|l|l|}
\hline \multicolumn{2}{|c|}{ Access this article online } \\
\hline Quick Response Code: & Website: \\
\hline & www.jnaccjournal.org \\
\cline { 2 - 3 } & \\
\hline
\end{tabular}

\section{HISTORY}

Craniopharyngiomas were first identified by Zenker in 1857. Later, histological origin of these tumours from hypophyseal duct or Rathke's pouch was first postulated by Mott and Barrett in 1899 and later the same was confirmed by Erdheim in 1904. The widely used term "craniopharyngioma" for these tumours was introduced by Cushing in 1932.

\section{INCIDENCE AND PREVALENCE}

The incidence of these tumours varies from 0.13 to 2 per 1 lakh population per year, with a point prevalence of approximately 1-3 per 1 lakh population..$^{[3]}$ There is no predilection to race or gender. The age of presentation is bimodal, children 5-14 years and elderly $65-74$ years of age. ${ }^{[4]}$ They represent about $2 \%-6 \%$ of all paediatric primary intracranial tumours and around $50 \%$ of all sellar/parasellar tumours. Congenital craniopharyngioma has been described in the literature. It was diagnosed in the antenatal period and later was radically excised after birth. ${ }^{[5]}$

This is an open access article distributed under the terms of the Creative Commons Attribution-NonCommercial-ShareAlike 3.0 License, which allows others to remix, tweak, and build upon the work non-commercially, as long as the author is credited and the new creations are licensed under the identical terms.

For reprints contact: reprints@medknow.com

How to cite this article: Moningi S. Anaesthetic management of children with craniopharyngioma. J Neuroanaesthesiol Crit Care 2017;4:S30-7. 


\section{CLASSIFICATION BASED ON AETIOLOGY}

Based on the embryology and histology, they are commonly classified into two types:[6]

1. Adamantinomatous tumours: (a) They arise from the epithelial remnants of the Rathke's pouch or the craniopharyngeal duct, (b) the location of the tumour is explained by this embryogenesis, and (c) this is more common in children. The incidence of recurrence is high and they are locally invasive tumours. ${ }^{[7]}$

2. Squamous papillary: (a) These result from the metaplasia of squamous epithelial cells at the junction of the pituitary stalk and pars distalis and (b) it is more common in adults.

3. Transitional or mixed types.

Craniopharyngiomas are avascular tumours, either displace or encase the vessels of circle of Willis, depending upon the site, growth and invasiveness of the tumour. Sellar tumours may present with sellar enlargement due to erosion of the floor of the sella.

According to the location of the tumour, they may be sellar, suprasellar, parasellar, retrosellar and infrasellar or multicompartmental. They are rarely malignant but have the propensity for local invasion. A recent classification of craniopharyngiomas was based on the site of tumour origin and tumour-meningeal relationship: (a) infrasellar infra-diaphragmatic, common in children, (b) suprasellar, subarachnoid extraventricular; common in adults and rarely seen in children and (c) suprasellar subpial types, seen both in adults and children. ${ }^{[8]}$

\section{CLINICAL PRESENTATION}

The clinical presentation and its severity vary depending on the size and site of the tumour and its growth potential. ${ }^{[3,9,10]}$ Usually, a time gap of $1-2$ years is seen before the diagnosis is established because of its sluggish growth. The clinical presentations include [Table 1] as follows:

1. Symptoms of raised intracranial tension: It may present with headache, nausea and vomiting either due to mass effect or due to obstruction of the cerebrospinal fluid (CSF) outflow pathway at the level of foramen of Monro, third ventricle or aqueduct of Sylvius. ${ }^{[11]}$

2. Endocrine disturbances: Short stature is a common finding in children due to growth hormone deficiency. Others include impotence, amenorrhea, hypothyroidism, diabetes insipidus (DI) and orthostatic hypotension and sometimes with hyperfunctionality such as precocious puberty in children. Obesity and lethargy are common in children. ${ }^{[11]}$

3. Another common presentation is due to compression on the adjacent optic nerve pathway leading to visual disturbances, for example, bitemporal hemianopia (inferior chiasmatic compression), homonymous anopsia, scotoma and optic atrophy with papilloedema. ${ }^{[11,12]}$

Other presenting symptoms are neck stiffness and seizures related to chemical meningitis (due to rupture of the cysts contents) and decreased functional activity and behavioural changes (hypothalamic damage due to local invasion) in children. Hypothalamic damage and endocrine disturbances are more common in children and ensue before the appearance of visual

Table 1: Craniopharyngioma and clinical presentation

\begin{tabular}{ll}
\hline $\begin{array}{l}\text { Clinical presentation according to site of involvement } \\
\text { or due to compression of vital structures }\end{array}$ & Symptomatology \\
\hline Neurologic & $\begin{array}{l}\text { Headache, cranial nerve palsy, motor disorders (hemi- } \\
\text { or mono-paresis) } \\
\text { Homonymous temporal hemianopia, scotoma, optic } \\
\text { atrophy } \\
\text { Visual pathways }\end{array}$ \\
$\begin{array}{l}\text { Growth failure, diabetes inspidus, hypogonadism, } \\
\text { precocious puberty, SIADH } \\
\text { Endocrinological (pituitary) }\end{array}$ & $\begin{array}{l}\text { Aphagia, obesity, poor energy, somnolence, psychiatric } \\
\text { symptoms (emotional lability, hallucinations, paranoic } \\
\text { delusions), autonomic disturbances }\end{array}$ \\
Hypothalamic & $\begin{array}{l}\text { Cognitive dysfunction, seizures } \\
\text { Headaches, nausea and vomiting, papilloedema, } \\
\text { decreased consciousness, coma }\end{array}$ \\
Brain parenchyma & -
\end{tabular}

$\mathrm{SIADH}=$ Syndrome of inappropriate secretion of anti-diuretic hormone 
symptoms. The incidence of hypothalamic disturbances is more with suprasellar subpial type. ${ }^{[13]}$ Involvement of the thalamus and frontal lobe may present with hyperphagia, psychomotor retardation, short-term memory deficits, emotional immaturity, apathy and incontinence. ${ }^{[14]}$ Other symptoms include growth failure and delayed puberty in young patients. Rarely, these tumours may locally spread to the brainstem and present with signs and symptoms (S and S) of brainstem dysfunction.

The incidence of recurrence is too high for these tumours, both in local and meningeal vicinity, which adds to increased morbidity. Multiple recurrences and post-radiotherapy (RT) may present with a malignant change, and this is very rare. ${ }^{[15]}$

These patients may actually present to the ophthalmology outpatient department (OPD) or surgical OPD either for visual disturbances or growth abnormalities.

\section{TREATMENT}

The mainstay of therapeutic management is to cure the disease with preservation and restoration of the functional activity.

1. Medical management: Hormonal replacement therapy is instituted for any endocrine abnormalities present.

2. Surgical approach ${ }^{[16,17]}$ - biopsy, subtotal or total excision of the tumour. Total excision is attempted wherever possible to prevent recurrence of the tumour ${ }^{[18]}$

a. Small tumours restricted to sella - endoscopic transnasal trans-sphenoidal approach; ${ }^{[19]}$ but rarely done in children (because of the developing sinuses, anatomy and small nares compared to adults); increased chances of CSF leak but decreased risk of visual injury.

b. Large tumours far beyond sella - craniotomy and radical excision or extended or far extended endoscopic trans-sphenoidal approach.

c. Keyhole or minimally invasive approaches through supraorbital incision - advantages include decreased dural leak and cosmetic incision [Figure 1] ${ }^{[20]}$

3. RT - after biopsy, subtotal excision or in recurrent tumours. ${ }^{[16,21]}$

4. Intracystic RT.

5. Chemotherapy - with bleomycin.

6. Aspiration - if mass is purely cystic.

7. Emergency Ommaya reservoir or biventricular shunt in children with giant tumours.

The most common indication for surgery is local invasion or compression effect of the tumour leading to symptomatology.

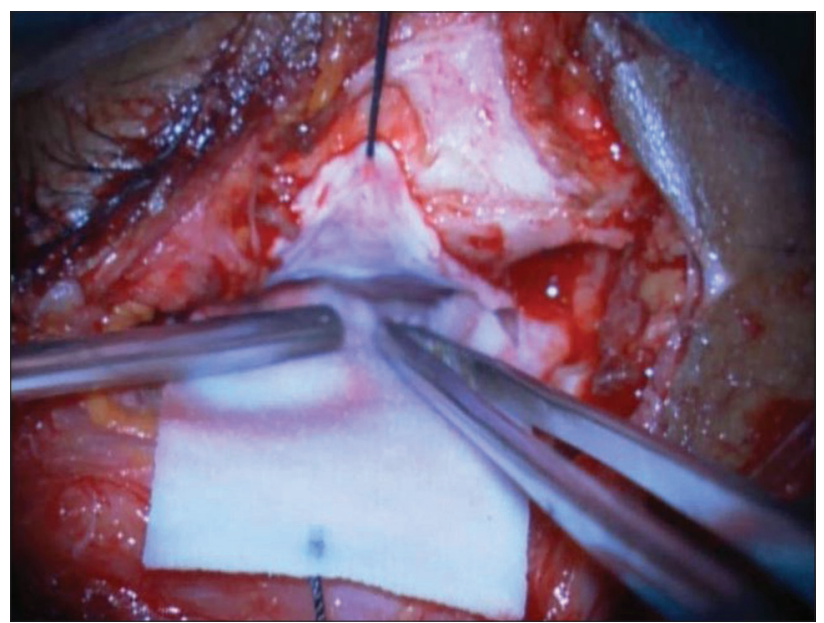

Figure 1: Supraorbital keyhole sub-frontal approach for excision of suprasellar cystic craniopharyngioma

\section{PRE-OPERATIVE CONCERNS}

1. History taking: Clinical presentation and neurological assessment guide us to the diagnosis.

2. Endocrine evaluation is done to identify abnormalities in endocrine function such as thyroid function tests, growth hormone, cortisol levels, sex hormones, adrenocorticotropic hormone and prolactin. ${ }^{[2]}$ Hypoadrenalism, DI and hypothyroidism have shown to have significant morbidity and mortality and should be normalised before any elective surgery. In cases of emergency, both hypoadrenalism and DI should be evaluated and treatment started before surgery.

3. Magnetic resonance imaging (MRI) with or without contrast enhancement is the diagnostic modality for screening craniopharyngiomas and helps in planning the surgical approach. T1-weighted images demonstrate hyperintense for the cystic component and isointense for the solid component, with enhancement of the rim and the tumour nodule. In T2-weighted images, both the cystic and solid component demonstrate hyperintensity [Figure 2]. ${ }^{[23]}$

4. Computed tomography of the brain is an alternative screening tool for its diagnosis. Craniopharyngiomas are heterogenous tumours, cystic component being hypodense and solid component being isodense with variable enhancement (with contrast). The presence of calcification $(90 \%)$ is suggestive of diagnosis of craniopharyngioma [Figure 3]. ${ }^{[23]}$

5. Ophthalmological assessment should include visual acuity, field of vision and retinoscopy for papilloedema. ${ }^{[24]}$

6. Special considerations include:

a. Patientswithlow cortisollevelsaresupplemented with steroids and optimised before elective 


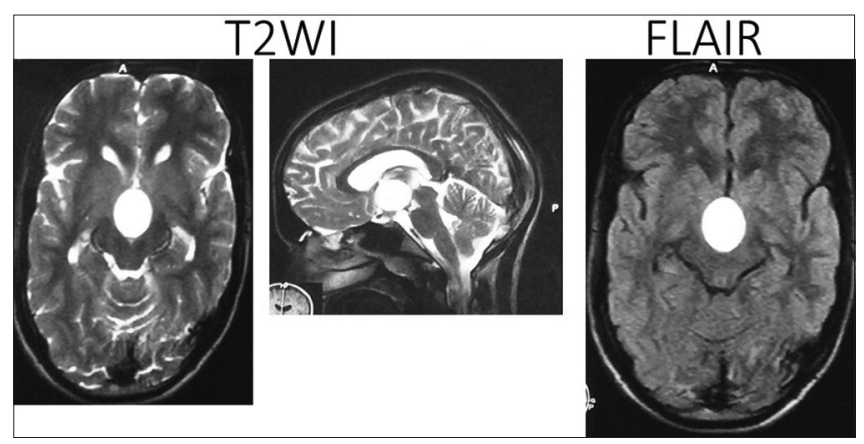

Figure 2: T2-weighted coronal and sagittal magnetic resonance imaging showing hyperintense suprasellar lesion; flair image confirming hyperintense lesion suggestive of cystic lesion

surgery. ${ }^{[25,26]}$ In children, hydrocortisone is given in an oral dose of $10-15 \mathrm{mg} / \mathrm{m}^{2} /$ day, either in two or three divided doses.

b. DI is a common finding treated with fluid management, vasopressin or desmopressin. ${ }^{[25]}$ Desmopressin is safely used in an oral dose of $0.05 \mathrm{mg}$ twice daily in children. Although it is 20 times less potent than nasal form, the safety and flexibility of dosing have replaced the nasal form of desmopressin. Lysine vasopressin can also be used in a dose of 2.5-10 units intramuscularly/subcutaneous/intranasally twice or thrice daily. ${ }^{[27]}$

c. Thyroid stimulating hormone (TSH) levels is the main target to treat hypothyroidism. Thyroxine tablets should be supplemented to normalise the TSH levels at least to $<10-12 \mathrm{mIU}$ or till the symptoms are normalised. The oral dose recommended for children $6-10$ years of age is $4-5 \mu \mathrm{g} / \mathrm{kg} /$ day.

d. Airway in paediatrics is completely different from adults. Short stature and obese children pose challenges in airway management. Proper airway assessment is mandatory in special category of cases with hypothalamic involvement. ${ }^{[28]}$

e. Although the tumour is avascular, vicinity of the tumour to adjoining vessels may present with vascular damage and increased chances of bleeding. This requires meticulous and vigilant management during acute and sudden blood loss. ${ }^{[29]}$

f. Obese children may have associated respiratory problems and obstructive sleep apnoea (OSA). These patients should be identified preoperatively and categorised as high-risk candidates.

g. Risk stratification: Age more than 5 years, tumour size $<4 \mathrm{~cm}$, complete surgical removal and absence of severe endocrinological dysfunction are the conditional criteria required for a favourable prognosis.

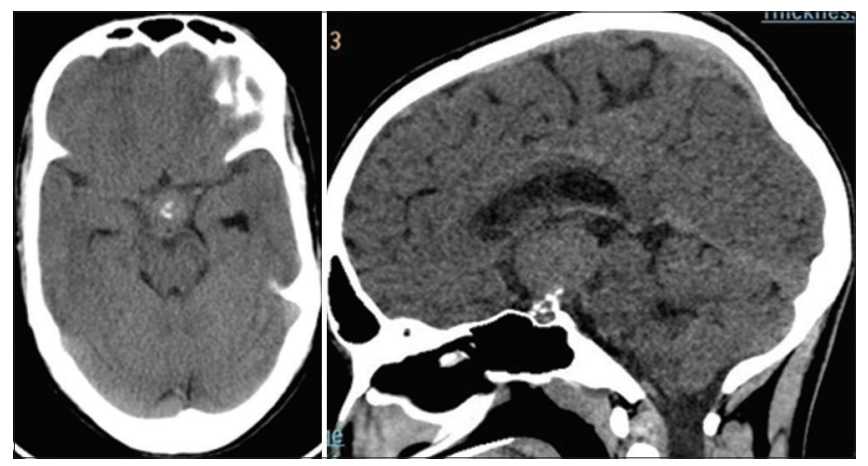

Figure 3: Computed tomography scan of the brain showing isodense suprasellar mass with specks of calcification suggestive of craniopharyngioma

Another important grading to judge the severity of the lesion and surgical decision in children speaks of three grades: Type 0 - no hypothalamic involvement, Type 1 - distorts or elevates the hypothalamus and Type 2 - hypothalamus is not visible. ${ }^{[12]}$

These grading systems give an overall picture of the incidence of post-operative morbidity, plan of surgery, anticipated problems and anaesthetic plan and management accordingly.

h. Children and their parents are counselled regarding the diagnosis, extent of the lesion, anaesthesia technique, surgical approach, positioning during surgery, possible complications and post-operative intensive care stay.

i. Volume status and electrolyte disturbances are monitored and corrected, especially in children with $S$ and $S$ of increased ICP and receiving mannitol. ${ }^{[30]}$ Patients with preoperative DI, due to nocturnal enuresis, may present with hypovolaemia on the morning of surgery. These children should be cautiously handled for haemodynamic instability at the time of induction.

j. All the children are advised nil orally at least for $6 \mathrm{~h}$ for solids and $2 \mathrm{~h}$ for clear liquids as per the American Society of Anesthesiologists guidelines.

k. Patients on replacement hormonal therapy should receive their morning doses of drugs. Children on antiepileptic agents for seizure management are continued on the day of surgery. This may have an effect on the neuromuscular blocking effect of non-depolarising muscle relaxants. ${ }^{[31]}$

1. Neurocognitive testing is important in children showing deterioration in school performance. ${ }^{[14]}$

$\mathrm{m}$. Premedication with sedatives is not mandatory, especially in children with $S$ and $S$ of increased ICP. Anxious children without any signs of 
increased ICP may be advised mild sedatives such as trichlorofos $100-125 \mathrm{mg} / \mathrm{kg}$ or alprazolam $0.25 \mathrm{mg}$ under vigilant monitoring.

n. Informed consent is mandatory.

\section{INTRAOPERATIVE MANAGEMENT}

After proper identification of the patient and rechecking the medications and neurological status, children are shifted to the operation theatre in a trolley.

\section{MONITORING}

Routine monitoring includes oxygen saturation by pulse oximetry, heart rate, electrocardiography, capnography and temperature. Surgery for craniopharyngioma may be associated with sudden blood loss, sometimes hypothalamic and rarely brainstem stimulation. The potential for any vascular injury warrants placement of an arterial cannula for continuous vigilance and timely action. Systolic pressure variation monitoring guides us in identifying and treating volume deficit. It also assists in frequent sampling of blood gases, electrolytes, glucose and osmolality, especially for the treatment of DI.

DI is a common intraoperative complication of craniopharyngioma. Apart from urine output, central venous pressure (CVP) monitoring is required for the diagnosis and management of DI. This also helps in rapid replenishment of acute blood losses and for administration of vasoactive drugs.

\section{ANAESTHESIA}

Balanced anaesthesia is a requisite as for any craniotomy. The aim is to maintain cerebral perfusion pressure and avoid any increase in ICP or any variations in mean arterial pressure. ${ }^{[31]}$ Intravenous (IV) induction is ideal, but inhalational induction with sevoflurane is preferred in un-cooperative children and with difficult iv access. ${ }^{[30]}$ Multimodal analgesia is provided with IV fentanyl, paracetamol and scalp block. Maintenance of anaesthesia is accomplished with inhalational agents or total IV anaesthesia with intermittent or continuous infusion of a short-acting opioid (such as fentanyl or remifentanil) and neuromuscular blocking agent (atracurium). Inhalational anaesthetics such as isoflurane are administered at 0.8-1.2 minimum alveolar concentration to avoid cerebral vasodilation and further aggravation of ICP. Anaesthetics such as propofol or dexmedetomidine infusions may be used as anaesthetic adjuvants. ${ }^{[32]}$

A motionless and bloodless surgical field is essential for clear and clean plane of dissection, identification of vital structures and excision of the tumour mass. ${ }^{[32]}$ Maintaining the arachnoid layer around the tumour during tumour dissection and excision helps in preserving the neurovascular structures around the craniopharyngioma. Mannitol $(0.25-1 \mathrm{~g} / \mathrm{kg})$ and other ICP lowering interventions are carried out for children with increased ICP. Sometimes, emergent decompressive craniectomy is required for sudden and acute presentation of patients with tumours obstructing at the level of fourth ventricle and aqueduct of Sylvius.

Airway management is crucial in paediatrics, more so in short-statured and obese children. Intubation may require bougie, video laryngoscope, fibre-optic bronchoscope and other airway equipment for handling a difficult paediatric airway. Opioids are administered in low doses or avoided, especially in children with OSA.

\section{SURGICAL POSITION}

The surgical approach dictates the position of the patient. ${ }^{[32]}$ Supine position with head tilt is the most commonly advocated one. The Mayfield frame is used to fix the head with paediatric pins or head is supported in a horseshoe frame. Application of skull pins in paediatric patients carries the danger of intracranial haematoma, dural tear and skull fracture. Careful positioning is done keeping in view of any airway compromise, venous congestion of the neck, IV access, padding of pressure points and protection of the eyes. Gross rotation of the head or neck flexion is avoided for any increase in venous pressure and for any inward migration of the endotracheal tube.

\section{VASCULAR ACCESS AND FLUID OF CHOICE}

Two large bore cannulas would suffice for any craniotomy in paediatric patients. This would take care of any unexpected and sudden blood loss. Central venous catheter may be required depending on the size of the tumour and extent of the radical excision. This is beneficial especially in patients suspected of developing DI or already established DI. Arterial pressure with systolic pressure variation monitoring is an important requisite for the chances of blood loss and haemodynamic instability during surgery is increased with radical excision of the tumour.

Normovolaemia is the accepted criteria for perioperative fluid management in neurosurgery. Normal saline is the fluid of choice for all intracranial neurosurgical procedures as it is slightly hyperosmolar and attenuates cerebral oedema. ${ }^{[33]}$ Balanced salt solutions have replaced normal saline in many of the centres, for they have shown to have better control over the acid-base balance and electrolyte status. Hypoglycaemia is a common presentation in paediatric patients undergoing major surgery, and on the other hand, hyperglycaemia 
exacerbates neurologic injury if ischaemia occurs. Frequent monitoring of blood glucose and timely and appropriate management of glucose disturbances are essential.

\section{INTRAOPERATIVE CONCERNS}

1. Injury to adjacent neural structures: Manipulation or any injury to the optic nerve and optic chiasm may result in deterioration of the vision.

2. Steroid replacement is an essential component for major surgery in these patients. These children require an initial dose of $0.5-1 \mathrm{mg} / \mathrm{kg}$ of hydrocortisone IV every $6 \mathrm{~h}$ at least for $72 \mathrm{~h}$.

3. Because of the close vicinity of the ICA and other vessels of the circle of Willis and due to the local invasion of the tumour, bleeding is a major concern. Controlling the depth of anaesthesia with lower side of the normal blood pressure is important to minimise the blood loss. Estimation of the blood volume and calculation of maximum allowable blood loss is essential and should be determined in advance for effective management of blood loss and its transfusion in paediatrics. Since the tumour is avascular, pharmacological agents such as tranexamic acid may not be useful. Sometimes, uncontrolled bleeding may result in cardiac arrest and increased mortality. ${ }^{[32]}$

4. DI is the most anticipated intraoperative complication. This occurs due to injury to the pituitary stalk or hypothalamus, resulting in decreased anti-diuretic secretion and diminished ability to concentrate urine. The incidence following transcranial excision is around $60 \%-70 \%$. It is characterised by increased output $(\geq 4 \mathrm{ml} / \mathrm{kg} / \mathrm{h}$ in $24 \mathrm{~h})$ of dilute urine
$(<300 \mathrm{mOs} / \mathrm{kg})$. Volume replacement is the main line of treatment with continuous monitoring of CVP, acid-base, osmolality and electrolyte changes and glucose. If it is associated with hypernatremia (>150 mg/dl), a hypo-osmolar fluid is preferred. To avoid rapid correction of sodium levels and its deleterious effects, the fall in sodium levels should be targeted at $0.5 \mathrm{mmol} / \mathrm{L} / \mathrm{hr}$. Continuous infusion of arginine vasopressin with deficit directed fluid management is useful in the intraoperative management of DI [Algorithm]. ${ }^{[34]}$

5. Hypothalamic disturbances may result in loss of temperature homoeostasis. Stimulation of the anteromedial hypothalamus may induce ST-T changes, which may be misleading towards cardiac ischaemia. ${ }^{[35]}$

6. Injury to mammillothalamic tract, thalamus and basal forebrain may result in children undergoing radical excision of the tumour. ${ }^{[36]}$

7. Brainstem injury is rare but may occur in cases with widespread invasion. ${ }^{[37]}$ Sometimes, the patient may require Intensive Care Unit admission in a comatose state.

8. Hypotension not responding to vasoactive drugs may be seen in patients with severe hypoadrenalism. Hydrocortisone in a dose of $1-2 \mathrm{mg} / \mathrm{kg}$ may be beneficial.

9. As the conventional craniotomy involves frontal lobe retraction and manipulation, seizures are common in the post-operative period. These patients are administered antiepileptics such as IV phenytoin $10 \mathrm{mg} / \mathrm{kg}$ as a loading dose for prophylaxis soon after excision of the tumour in the intraoperative period and are continued in the PO period. Patients with symptomatology of seizures and on anti-seizure treatment will receive

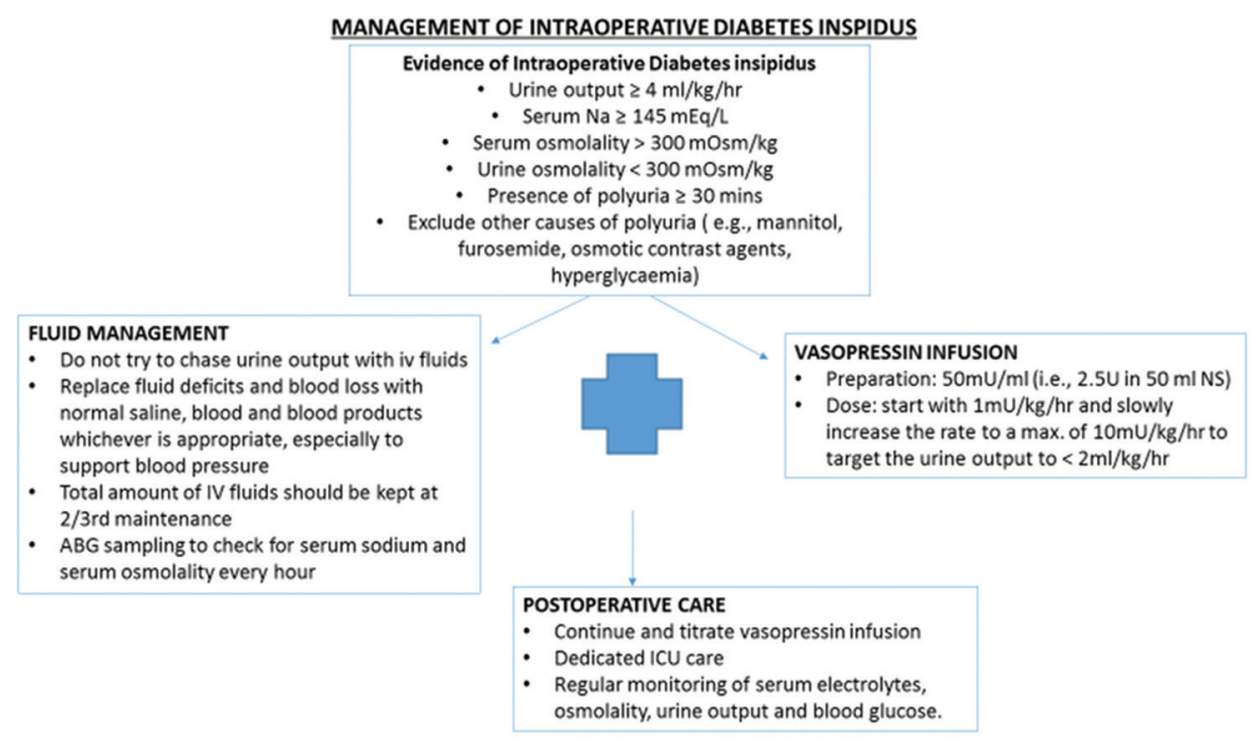

Algorithm: Intraoperative management of diabetes insipidus. $\mathrm{Na}=$ Sodium; ABG = Arterial blood gas; ICU = Intensive Care Unit 
their maintenance dose of antiepileptic drug in the intraoperative period.

10. CSF leakage: more commonly seen in children undergoing trans-sphenoidal approach. ${ }^{[38]}$

The duration of surgery depends on the extent of the lesion, surgical plan, surgical expertise and surgical field conditions. The patients with an uneventful intraoperative period may be extubated on table.

\section{POST-OPERATIVE CONCERNS}

1. Pain: Post-operative pain is a major concern as expression of pain is different in paediatric patients with increased crying, restlessness, etc. Analgesic priming with injection fentanyl, injection paracetamol and infiltration analgesia are helpful in combating post-operative pain.

2. Fluid management: Normovolaemia should be maintained with the use of normal saline.

3. The intraoperative problems such as DI may carry onto the PO period. The incidence is around $70 \%-90 \%$. Details are already described in the intraoperative concerns. ${ }^{[35]}$ Others symptoms of DI such as loss of thirst is unmasked in the PO period. These children pose a high risk for hypernatraemia. Nasal desmopressin is effective in the dose of DI present in the pre-operative period. DI may improve after surgery, but other endocrine abnormalities rarely improve.

4. Other features of hypopituitarism, such as anterior and posterior pituitary dysfunction, may be seen. The incidence is around $50 \%-100 \%$. After $48-72 \mathrm{~h}$ of supraphysiologic doses of steroid replacement, the dose is maintained or tapered down to physiologic doses of hydrocortisone depending on the daily morning cortisol levels. ${ }^{[39]}$ Some of the patients receive steroids for long-term to balance the hypothalamo-pituitary axis.

5. In children undergoing radical surgery, hypothalamic dysfunction such as hyper- or hypo-thermia, behavioural and memory changes may be evident. These children with loss of temperature homoeostasis and somnolence have a very bad prognosis. ${ }^{[35,40]}$

6. Post-operative seizures: They are common following craniotomy surgery and respond promptly to anti-seizure treatment. They rarely occur following trans-sphenoidal surgery.

7. Obese children with established diagnosis of OSA may have difficulty in weaning from ventilation and in due course may develop respiratory infections and become ventilator dependent. Careful and timely weaning of these children is important to avoid these complications.

8. Patients with severe dyselectrolytaemia, haemodynamic instability, hypothalamic injury, changes in osmolality and acid-base may require PO elective respiratory support.

9. Residual tumour: MRI scan is repeated in the post-operative period to evaluate the extent of lesion which may be responsible for the delayed appearance of symptoms. Most of the patients with residual tumour are effectively treated with RT. RT is like a double-edged sword. RT following surgery is very effective in regression of the tumour, but at the same time, it may have its effect on intelligence quotient and growth. Delayed RT is preferred in paediatric patients to avoid this effect.

10. Follow-up of the neurocognitive function in the post-operative period is essential to understand the quality of life in children, especially with pre-operative changes, and following subtotal resection and radiotherapy. ${ }^{[14]}$

11. Rarely, patients may develop radiation-induced gliomas, the mostcommon site being the temporal lobe. Other side effects of RT are endocrine dysfunction, optic neuritis, dementia and radiation necrosis.

\section{CONCLUSION}

Pre-operative evaluation and proper planning with the knowledge of the extent of lesion and symptomatology are the keys to right surgical decision and optimal anaesthetic management. The myriad of endocrinological disturbances in the perioperative period does not limit the job of neuroanaesthesiologist just to the intraoperative period. For the overall success of the outcome, the post-operative prevention and management of complications and maintaining the balance of the hypothalamo-pituitary axis with replacement therapy plays a major role.

\section{Financial support and sponsorship}

Nil.

\section{Conflicts of interest}

There are no conflicts of interest.

\section{REFERENCES}

1. Stamm AC, Vellutini E, Balsalobre L. Craniopharyngioma. Otolaryngol Clin North Am 2011;44:937-52, viii.

2. Bajwa SJ, Bajwa SK, Bindra GS. The anesthetic, critical care and surgical challenges in the management of craniopharyngioma. Indian J Endocrinol Metab 2011;15:123-6.

3. Müller HL. Craniopharyngioma. Endocr Rev 2014;35:513-43.

4. Bunin GR, Surawicz TS, Witman PA, Preston-Martin S, Davis F, Bruner JM. The descriptive epidemiology of craniopharyngioma. J Neurosurg 1998;89:547-51.

5. Kageji T, Miyamoto T, Kotani Y, Kaji T, Bando Y, Mizobuchi Y, et al. Congenital craniopharyngioma treated by radical surgery: Case report and review of the literature. Childs Nerv Syst 2016. [Epub ahead of print].

6. Fernandez-Miranda JC, Gardner PA, Snyderman $\mathrm{CH}$, 
Devaney KO, Strojan P, Suárez C, et al. Craniopharyngioma: A pathologic, clinical, and surgical review. Head Neck 2012;34:1036-44.

7. Pekmezci M, Louie J, Gupta N, Bloomer MM, Tihan T. Clinicopathological characteristics of adamantinomatous and papillary craniopharyngiomas: University of California, San Francisco experience 1985-2005. Neurosurgery 2010;67:1341-9.

8. Müller HL. Preoperative staging in childhood craniopharyngioma: Standardization as a first step towards improved outcome. Endocrine 2016;51:1-3.

9. Meuric S, Brauner R, Trivin C, Souberbielle JC, Zerah M, Sainte-Rose C. Influence of tumor location on the presentation and evolution of craniopharyngiomas. J Neurosurg 2005;103 5 Suppl: 421-6.

10. Karavitaki N, CudlipS,Adams CB, WassJA. Craniopharyngiomas. Endocr Rev 2006;27:371-97.

11. Müller HL. Craniopharyngioma. Handb Clin Neurol 2014;124:235-53.

12. Puget S, Garnett M, Wray A, Grill J, Habrand JL, Bodaert N, et al. Pediatric craniopharyngiomas: Classification and treatment according to the degree of hypothalamic involvement. J Neurosurg 2007;106 1 Suppl: 3-12.

13. Pan J, Qi S, Liu Y, Lu Y, Peng J, Zhang X, et al. Growth patterns of craniopharyngiomas: Clinical analysis of 226 patients. J Neurosurg Pediatr 2016;17:418-33.

14. Sands SA, Milner JS, Goldberg J, Mukhi V, Moliterno JA, Maxfield C, et al. Quality of life and behavioral follow-up study of pediatric survivors of craniopharyngioma. J Neurosurg 2005; 1034 Suppl: 302-11.

15. Nelson GA, Bastian FO, Schlitt M, White RL. Malignant transformation in craniopharyngioma. Neurosurgery 1988;22:427-9.

16. Ali ZS, Bailey RL, Daniels LB, Vakhshori V, Lewis DJ, Hossain AT, et al. Comparative effectiveness of treatment options for pediatric craniopharyngiomas. J Neurosurg Pediatr 2014;13:178-88.

17. Clark AJ, Cage TA, Aranda D, Parsa AT, Sun PP, Auguste KI, et al. A systematic review of the results of surgery and radiotherapy on tumor control for pediatric craniopharyngioma. Childs Nerv Syst 2013;29:231-8.

18. Di Rocco C, Caldarelli M, Tamburrini G, Massimi L. Surgical management of craniopharyngiomas - Experience with a pediatric series. J Pediatr Endocrinol Metab 2006;19 Suppl 1:355-66.

19. Kenning TJ, Beahm DD, Farrell CJ, Schaberg MR, Rosen MR, Evans JJ. Endoscopic endonasal craniopharyngioma resection. J Neurosurg 2012;32:E5.

20. Ormond DR, Hadjipanayis CG. The supraorbital keyhole craniotomy through an eyebrow incision: Its origins and evolution. Minim Invasive Surg 2013;2013:296469.

21. Lee M, Kalani MY, Cheshier S, Gibbs IC, Adler JR, Chang SD. Radiation therapy and CyberKnife radiosurgery in the management of craniopharyngiomas. Neurosurg Focus 2008;24:E4.

22. Stiller CA, Nectoux J. International incidence of childhood brain and spinal tumours. Int J Epidemiol 1994;23:458-64.

23. Curran JG, O'Connor E. Imaging of craniopharyngioma. Childs Nerv Syst 2005;21:635-9.

24. Defoort-Dhellemmes S, Moritz F, Bouacha I, Vinchon M. Craniopharyngioma: Ophthalmological aspects at diagnosis. J Pediatr Endocrinol Metab 2006;19 Suppl 1:321-4.

25. Bajwa SJ, Kaur G. Endocrinopathies: The current and changing perspectives in anesthesia practice. Indian J Endocrinol Metab 2015; 19:462-9.

26. Inder WJ, Hunt PJ. Glucocorticoid replacement in pituitary surgery: Guidelines for perioperative assessment and management. J Clin Endocrinol Metab 2002;87:2745-50.

27. Mishra G, Chandrashekhar SR. Management of diabetes insipidus in children. Indian J Endocrinol Metab 2011;15 Suppl 3:S180-7.

28. Vinchon M, Weill J, Delestret I, Dhellemmes P. Craniopharyngioma and hypothalamic obesity in children. Childs Nerv Syst 2009;25:347-52.

29. Tomita T, Bowman RM. Craniopharyngiomas in children: Surgical experience at Children's Memorial Hospital. Childs Nerv Syst 2005;21:729-46.

30. Rath GP, Dash HH. Anaesthesia for neurosurgical procedures in paediatric patients. Indian J Anaesth 2012;56:502-10.

31. Furay C, Howell T. Paediatric neuroanaesthesia. Contin Educ Anaesth Crit Care Pain 2010;10:172-6.

32. Cottrell JE, Young WL. Cottrell and Young's Neuroanesthesia. Philadelphia: Elsevier Health Sciences; 2016.

33. Tommasino C, Picozzi V. Volume and electrolyte management. Best Pract Res Clin Anaesthesiol 2007;21:497-516.

34. Wise-Faberowski L, Soriano SG, Ferrari L, McManus ML, Wolfsdorf JI, Majzoub J, et al. Perioperative management of diabetes insipidus in children [corrected]. J Neurosurg Anesthesiol 2004;16:14-9.

35. Cohen M, Bartels U, Branson H, Kulkarni AV, Hamilton J. Trends in treatment and outcomes of pediatric craniopharyngioma, 1975-2011. Neuro Oncol 2013;15:767-74.

36. lizuka O, Suzuki K, Mori E. Severe amnesic syndrome and collecting behavior after surgery for craniopharyngioma. Cogn Behav Neurol 2007;20:126-30.

37. Grover WD, Rorke LB. Invasive craniopharyngioma. J Neurol Neurosurg Psychiatry 1968;31:580-2.

38. Jane JA Jr., Prevedello DM, Alden TD, Laws ER Jr. The transsphenoidal resection of pediatric craniopharyngiomas: $A$ case series. J Neurosurg Pediatr 2010;5:49-60.

39. Coté CJ, Lerman J, Anderson BJ. A Practice of Anesthesia for Infants and Children: Expert Consult-Online and Print. Pennsylvania: Elsevier/Saunders; 2013.

40. Müller HL. Childhood craniopharyngioma: Current controversies on management in diagnostics, treatment and follow-up. Expert Rev Neurother 2010;10:515-24. 